\title{
Anti-Diabetic Effects of Dung Beetle Glycosaminoglycan on db Mice and Gene Expression Profiling
}

\author{
Mi Young Ahn', Ban Ji Kim' ', Hyung Joo Yoon', Jae Sam Hwang' and Kun-Koo Park ${ }^{2}$ \\ ${ }^{1}$ Department of Agricultural Biology, National Academy of Agricultural Science, RDA, Wanju, Korea \\ ${ }^{2}$ Pharmacogenechips Inc., Chuncheon, Korea
}

\begin{abstract}
Anti-diabetes activity of Catharsius molossus (Ca, a type of dung beetle) glycosaminoglycan $(\mathrm{G})$ was evaluated to reduce glucose, creatinine kinase, triglyceride and free fatty acid levels in $\mathrm{db}$ mice. Diabetic mice in six groups were administrated intraperitoneally: Db heterozygous (Normal), Db homozygous (CON), Heuchys sanguinea glycosaminoglycan (HEG, $5 \mathrm{mg} / \mathrm{kg}$ ), dung beetle glycosaminoglycan (CaG, $5 \mathrm{mg} / \mathrm{kg}$ ), bumblebee (Bombus ignitus) queen glycosaminoglycan (IQG, $5 \mathrm{mg} / \mathrm{kg}$ ) and metformin $(10 \mathrm{mg} / \mathrm{kg}$ ), for $1 \mathrm{month}$. Biochemical analyses in the serum were evaluated to determine their anti-diabetic and anti-inflammatory actions in $\mathrm{db}$ mice after 1 month treatment with HEG, $\mathrm{CaG}$ or IQG treatments. Blood glucose level was decreased by treatment with CaG. CaG produced significant anti-diabetic actions by inhiting creatinine kinase and alkaline phosphatase levels. As diabetic parameters, serum glucose level, total cholesterol and triglyceride were significantly decreased in CaG5-treated group compared to the controls. Dung beetle glycosaminoglycan, compared to the control, could be a potential therapeutic agent with anti-diabetic activity in diabetic mice. CaG5-treated group, compared to the control, showed the up-regulation of 48 genes including mitochondrial yen coded tRNA lysine (mt-TK), cytochrome P450, family 8/2, subfamily b, polypeptide 1 (Cyp8b1), and down-regulation of 79 genes including S100 calcium binding protein A9 (S100a9) and immunoglobulin kappa chain complex (Igk), and 3-hydroxy-3-methylglutaryl-CoenzymeAsynthase1 (Hmgcs1). Moreover, mitochondrial thymidine kinase (mt-TK), was up-regulated, and calgranulin A (S100a9) were down-regulated by $\mathrm{CaG} 5$ treatment, indicating a potential therapeutic use for anti-diabetic agent.
\end{abstract}

Key words: Anti-diabetic effect, Queen of B. ignitus, Catharsius molossus, Glycosaminoglycan, Microarray

\section{INTRODUCTION}

Diabetes mellitus is a metabolic disease associated with systemic damages to microvessel of kidney and other organs (1). With decreasing morbidity, many drugs from natural product and synthetic chemicals have been developed as anti-diabetic agents. Early stages of diabetic nephropathy are characterized by low urinary excretion of albumin, with glomerular basement membrane functioning by charge-dependent permeability due to the presence

Correspondence to: Mi Young Ahn, Department of Agricultural Biology, National Academy of Agricultural Science, RDA, 166 Nongsaengmyung-ro, Iseo-myun, Wanju 55365, Korea

E-mail: amy@korea.kr

This is an Open-Access article distributed under the terms of the Creative Commons Attribution Non-Commercial License (http:// creativecommons.org/licenses/by-nc/3.0) which permits unrestricted non-commercial use, distribution, and reproduction in any medium, provided the original work is properly cited. of anionic constituents, especially heparin sulfate [HS, a type of glycosaminoglycan (GAG)] proteoglycans (2). Among inherited metabolic disorders, particularly mucopolysaccharidoses, GAG degradation pathways are disrupted due to enzyme deficiency (3). Meanwhile, cellular oxidative damage could be repaired by expression of antioxidative enzymes (including superoxide dismutase and glutathione peroxidase) so that peroxided glycosylated lipids, proteins and nucleic acids could not be produced anymore (1). Sulodexide, a highly purified mixture of glycosaminoglycans composed of low molecular weight heparin and dermatan sulfate, has been recently developed for treatment of diabetic nephropathy. Clinical studies have suggested that Sulodexide therapy offers renal protection, capable of reducing urinary albumin excretion (4). According to a recent report, similar to Sulodexide (commercial glycosaminoglycan), some insect GAGs can also increase anti-oxidant activity and diminish cellular oxidative damage. After treatment with bumblebee queen glycosamino- 
glycan (IQG), activities of anti-oxidative enzyme, SOD and catalase are increased whereas oxidative stress parameter, carbonyl content (protein oxidative damage) and malondialdehyde (MDA, lipid denaturant) in high-fat diet rat hepatocyte were diminished by (5). Therefore, we designed this study to determine whether insect glycosaminoglycans might have a role in treating diabetes or increasing antioxidant enzyme activity under diabetes condition using, Homo diabetic (db) mice. An insect glycosaminoglycan was been prepared and purified from black and scarlet cicada (Huechys sanguinea) (6). Another insect glycosaminoglycan isolated from dung beetle (Catharsius molossus, Ca) also possesses anti-aging activities. It can reduce serum level of creatinine kinase with aortic vasorelaxant activities. It can also maintain normal glucose level in aged rat (7). As an apicultural product, bumblebee (Bombus ignitus) queen (BIQ) glycosaminoglycan is a potential agent for treating obesity in high-fat diet rats (5). Anti-diabetic gene targets of glycosaminoglycan in $\mathrm{db}$ mice have not been fully elucidated. In this study, we found that glycosaminoglycans such as HEG, $\mathrm{CaG}$ and IQG displayed anti-oxidant and anti-diabetic properties. They also changed gene expression profiling in $\mathrm{db}$ mice. The glycosaminoglycans might hold great promise as antidiabetic agents by reducing cellular oxidative damages.

\section{MATERIALS AND METHODS}

\section{Materials.}

Preparation of insect glycosaminoglycans: Dried $C$. molossus and H. sanguinea, were purchased at a local market in China. These crude drugs were obtained from insects identified by insect classification experts in the Department of Agricultural Biology, National Academy of Agricultural Science, South Korea. Bumble bee (B. ignitus) queen was reared and freeze-dried, in the same institute. Metformin was purchased from CJ Healthcare Co (Seoul, Korea).

Dried insect (1 kg each) was soaked and extracted three times with ethanol by ultrasonification for $30 \mathrm{~min}$. Residues were separated from alcohol extracts and were defatted twice with two volumes of acetone. Approximately $200 \mathrm{~g}$ of dried, defatted and pulverized powder was suspended in $2 \mathrm{~L}$ of $0.05 \mathrm{M}$ sodium carbonate buffer ( $\mathrm{pH} 9$ ). The suspension was incubated at $60^{\circ} \mathrm{C}$ for $48 \mathrm{hr}$ after adding $28 \mathrm{~mL}(1.4 \%)$ of Alcalase (Sigma Aldrich, St. Louis, MO, USA) for protein enzymatic hydrolysis. The digestion mixture was cooled to $4^{\circ} \mathrm{C}$. Trichloroacetic acid was added to a final concentration of $5 \%$. The sample was allowed to stand for $1 \mathrm{hr}$ followed by centrifugation at $8000 \times \mathrm{g}$ for $30 \mathrm{~min}$. Three volumes of $5 \%$ potassium acetate in ethanol were added to one volume of supernatant, stored overnight at $4^{\circ} \mathrm{C}$, and then centrifuged at $8,000 \mathrm{~g}$ for $30 \mathrm{~min}$. The precipitate $(20 \mathrm{~g})$ was dissolved in $40 \mathrm{~mL}$ of $0.2 \mathrm{M} \mathrm{NaCl}$ and centrifuged at $8,000 \mathrm{~g}$ for $30 \mathrm{~min}$.
Cetylpyridinium chloride (5\%) was added to 0.2 volumes of the supernatant followed by centrifugation $(8,000 \mathrm{~g}$ for $30 \mathrm{~min}$ ). The precipitate was dissolved in $20 \mathrm{~mL}$ of $2.5 \mathrm{M}$ $\mathrm{NaCl}$. Five volumes of ethanol were added followed by centrifugation at $8,000 \mathrm{~g}$ for $30 \mathrm{~min}$. The precipitate was then dissolved in water and dialyzed against 100 volumes of water (8). The dialyzed crude GAG was freeze-dried to obtain a concentration of up to $0.9 \%$. Crude GAG was loaded onto a DEAE Sephadex A-25 gel chromatography column $(40 \times 1.2 \mathrm{~cm})$ equilibrated with $50 \mathrm{mM}$ phosphate buffer ( $\mathrm{pH}$ 7.4). Fractions were eluted using a linear sodium chloride gradient from 0 to $2.5 \mathrm{M} \mathrm{NaCl}$ in phosphate buffer at a flow rate of $20 \mathrm{~mL} / \mathrm{hr}$. Dialyzed glycan was freeze-dried to obtain pure GAG.

Animals. BKS.Cg-m+/+Leprdb $(\mathrm{db} / \mathrm{db})$, heterozygous and homozygous male $\mathrm{db}$ mice at 12 -weeks of age, were purchased from Samtako Co. Ltd (Osan, Korea). All procedures were in accordance with NIH Guidelines for Care and Use of Laboratory Animals. All experiments were approved by Laboratory Animals' Ethical Committee of the National Academy of Agricultural Science (NIAS201605), Rural Development Administration, South Korea. All procedures followed national guidelines for the care and use of animals (individual housing). Mice were acclimated for 6 months under normal husbandry conditions (temperature, $23 \pm 2^{\circ} \mathrm{C}$; humidity, $55 \pm 10 \%$; and light/dark cycle, $12 \mathrm{hr} / 12 \mathrm{hr}$ ). They were provided free access to normal diet (D10001, AIN-76A rodent diet, Research Diet Inc., New Brunswick, NJ, USA) and water free access. These mice were allocated into two control groups and three treatment groups (11 mice per group). They were distributed according to similarity in weight $(28.86 \pm 2.36 \mathrm{~g})$. Treatments were given in PBS daily. Each treatment was administrated intraperitoneally. The following treatment groups were used: 1) Normal (DB-Hetero), 2) Control (DB-Homo), 3) $5 \mathrm{mg} / \mathrm{kg} \mathrm{HeG}$ (HeG5), 4) $5 \mathrm{mg} / \mathrm{kg} \mathrm{CaG}$ (CaG5), 5) $5 \mathrm{mg} / \mathrm{kg}$ IQG (IQG5), and 6) $10 \mathrm{mg} / \mathrm{kg}$ Metformin (Metformin10). Mice in each group were maintained with normal diet (AIN-76A rodent diet, Research Diet). Animal experimental design is shown in Fig. 1.

Body weight and blood glucose detection. Body weights were measured every week. Glucose levels were recorded weekly with glucose stick and using a blood glucose Nocodingone detector (Theragen Etex Co. Ltd., Sungnam, Korea). Serum glucose level at the last day of treated schedule, after one-month of treatment was recorded using an auto-analyzer. As a positive control, metformin, a hypoglycemic reagent for type 2 diabetes, was used in this study.

Organ and adipose tissue weights. Absolute and relative weights (organ-to-body ratio) were measured for 


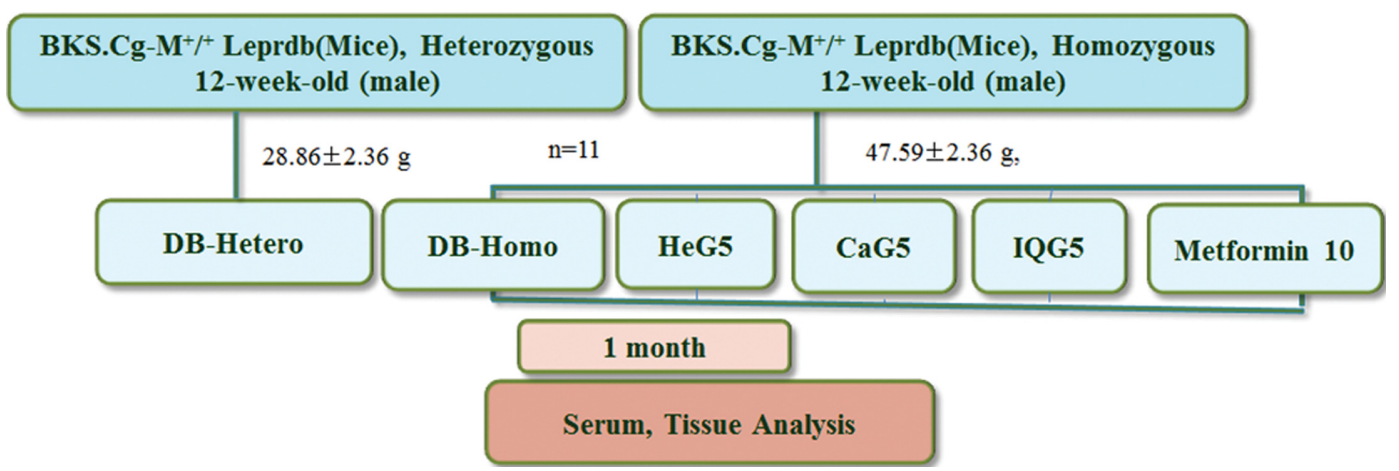

Fig. 1. Animal experimental design. HeG5; H. sanguinea (Hongrangja, Korean name) glycosaminoglycan $5 \mathrm{mg} / \mathrm{kg}$; $C$. molossus (dung beetle) glycosaminoglycan $5 \mathrm{mg} / \mathrm{kg}$; IQG5: B. ignitus (a type of bumblebee) queen glycosaminoglycan $5 \mathrm{mg} / \mathrm{kg}$, and Metformin10: Metformin $10 \mathrm{mg} / \mathrm{kg}$.

adrenal glands, kidneys, heart, liver, lung, spleen, stomach and pancreas. Abdominal fat to-body weight ratio was also determined. These measurements were made after sacrifice at the end of the one-month treatment period.

Blood sampling and serum assay. After treatment with $\mathrm{HeG} 5, \mathrm{CaG} 5$, IQG5, or metformin 10 treatment, for 1-month, all non-diabetic heterozygous control mice, $\mathrm{db}$ control mice, and $\mathrm{db}$ treated mice were sacrificed for serum assay and DNA microarray. Approximately $1 \mathrm{~mL}$ of blood was collected from the posterior vena cava under light $\mathrm{CO}_{2}$ inhalation and used for serum chemistry measurements The following parameters were examined: albumin, hyaluronic acid (HA), free fatty acid (FFA), alkaline phosphatase (ALP), glutamic oxaloacetic transaminase (AST), glutamic pyruvic transaminase (ALT), lactic dehydrogenase (LDH), creatinine phosphokinase (CK), glucose, total cholesterol triglyceride, high-density lipoprotein (HDL) cholesterol, low-density lipoprotein (LDL) cholesterol, creatinine, blood urea nitrogen (BUN), total protein, sodium $(\mathrm{Na})$, chloride $(\mathrm{Cl})$, c-reactive protein (CRP), calcium (ca), potassium (K), total IgE, C-peptide and insulin. These parameters were evaluated using an autoanalyzer (7060 Automatic Clinical Analyzer, Hitachi, Tokyo, Japan).

Adipocyte density. Excised organs and adipose tissue were fixed with $10 \%$ neutral formalin. After paraffin embedding and sectioning, sections were stained with hematoxylin and eosin (H\&E), and Toluidine blue $\mathrm{O}$, examined by light microscopy (CRT6000, Leica, Hesse, Germany), and photographed. Adipocyte densities (cells/ $\mathrm{mm}^{2}$ ) were determined for treated and control tissue by toluidine blue $\mathrm{O}$ stain (original magnification, $\times 400$ ).

Oxidative protein damage. Liver homogenate and blood were centrifuged $(8,000 \mathrm{~g}$ for $30 \mathrm{~min})$. Supernatants were used for determination of carbonyl content. Protein oxidative stress was evaluated by measuring pro- tein carbonyl content in the blood. Carbonyl content was determined with an enzyme-linked immunosorbent assay (ELISA) using OxiSelect ${ }^{\mathrm{TM}}$ protein carbonyl ELISA kit (Cell Biolabs, Inc., San Diego, CA, USA) according to the manufacturer's protocol. CAT activity (U/mg protein) was measured based on CAT-mediated decomposition of $\mathrm{H}_{2} \mathrm{O}_{2}(9)$.

Liver homogenate preparation for oxidative enzyme detection. Six groups (DB-Hetero, DB-Homo, HeG5, CaG5, IQG5, Metformin10) of liver tissues were homogenized on ice in a 10-fold volume lysis buffer PRO-PREP ${ }^{\mathrm{TM}}$ protein extraction solution (iNtRON, Busan, Korea). The supernatant of each liver homogenate after centrifugation (800 g, $10 \mathrm{~min}$ ) was assayed for catalase, glutathione peroxidase, glutathione s-transferase and superoxide dismutase activities using OxiSelect ${ }^{\mathrm{TM}}$ ELISA kit (Cell Biolabs, Inc.) according to the assay manual.

RNA preparation and quantitative real-time PCR analysis. Total RNA was isolated from liver tissue using TRIzol reagent (Invitrogen, Carlsbad, CA, USA). RNA concentration and purity were measured using a UV/Vis spectrophotometer (Beckman Coulter Co., Miami, FL, USA). Complementary DNA (cDNA) was synthesized from $1 \mathrm{mg}$ of total RNA using high capacity cDNA Reverse Transcription Kit (Amersham Biosciences Co., Piscataway, NJ, USA). Real-time polymerase chain reaction (PCR) amplification was performed using Power SYBR Green Master Mix on a 7500 Real-Time PCR System (Applied Biosystems, Fostercity, CA, USA), according to the manufacturer's instructions. For detection of target gene transcripts, we designed specific forward and reverse oligonucleotide primers using Beacon Designer software (PREMIER Biosoft, Palo Alto, CA, USA). The primer sequences are listed in Table 1. Target mRNA levels were normalized using glyceraldehyde 3-phosphate dehydrogenase (GAPDH) as an internal control to qualify the relative expression of target mRNA according to cycling threshold method. All sam- 
Table 1. Primer sequences for amplication of genes involved in glycogen metabolism and GAPDH internal standard

\begin{tabular}{|c|c|c|}
\hline Gene symbol & Gene name & Primer sequence \\
\hline Gpx1 & Glutathione peroxidase 1 & $\begin{array}{l}\text { 5'-CCAACACCCAGTGACGACC-3' } \\
\text { 5'-CTCAAAGTTCCAGGCAATGTC-3' }\end{array}$ \\
\hline Heparanase & Heparanase & $\begin{array}{l}\text { 5'-ACTTGAAGGTACCGCCTCCG-3' } \\
\text { 5'-GAAGCTCTGGAACTCGGCAA-3' }\end{array}$ \\
\hline GSK3b & Glycogen synthase kinase 3 beta & $\begin{array}{l}\text { 5'-tccgaggagagcccaatgtt-3' } \\
\text { 5'-acaccactgtccccaggaaa-3' }\end{array}$ \\
\hline SAA4 & Serum amyloid A4 & $\begin{array}{l}\text { 5'-gaaggcacggatgaagacgg-3' } \\
5 \text { '-acaggctccatccatcctcc-3' }\end{array}$ \\
\hline GAPDH & Glyceraldehyde-3-phosphate dehydrogenase & $\begin{array}{l}\text { 5'-GTGGAGATTGTTGCCATCAACGA-3' } \\
\text { 5'-CCCATTCTCGGCCTTGACTGT-3' }\end{array}$ \\
\hline
\end{tabular}

ples were analyzed in triplicate. Primer sequences for amplification of genes involved in cell repair mechanism and GAPDH internal standard (Table 1).

DNA microarray procedure. Microarray hybridization was performed for mouse liver samples. Total RNA was isolated from mice liver tissue using a Qiagen RNeasy Midi Kit (Qiagen, Valencia, CA, USA). A FairPlay ${ }^{\mathrm{TM}}$ microarray labeling kit (Stratagene, La Jolla, CA, USA) was used for DNA labeling according to the manufacturer's instructions. Labeled DNA was loaded onto a microarray chip. A hybridization chamber was assembled with the microarray chip of Mouse Gene 2.0 ST Arrays (Affymetrix Inc., Santa Clara, CA, USA), and submerged in a water bath at $60^{\circ} \mathrm{C}$ overnight. The microarray chip was washed with wash buffers I, II, and III. The slide was then dried by centrifuging and scanned with a BMS Array Scanner (Applied Precision Array WoRx eBiochip Reader (BioRad, Dallas, TX, USA) (10).

Statistical analysis. Means and standard errors of parameters were determined for each group using analysis of variance (ANOVA). Student's $t$-test was used to determine significant differences between control and treated groups. A $p$ value of less than 0.05 was considered statistically significant.

\section{RESULTS}

Yield of insect glycosaminoglycan. From $1 \mathrm{~kg}$ of each dried insect, the yield of freeze-dried GAG powder was about $8.8 \mathrm{~g}(0.88 \%)$ for $\mathrm{HEG}, 1.52 \mathrm{~g}(0.15 \%)$ for $\mathrm{CaG}$, and $2.8 \mathrm{~g}(0.28 \%)$ for IQG. Insect shells left after preparation of alcoholic extract from these three species of insects were dried. About $1 \mathrm{~g}$ was obtained after drying. Proteins were removed with proteases. After removing impurities by precipitation, supernatant was dialyzed with distilled water. For treating db mice for diabetic study, protein was prepared by collecting sugar acid fraction followed by purification with salt gradient ( 0 to $2.5 \mathrm{M} \mathrm{NaCl}$ in phosphate buffer) via strong anion exchange (SAX) and gel filtration chromatography using DEAE Sephadex A-25. Fraction containing uronic acids were collected. To determine GAG purity, digested GAG, oligosaccharides mixture by GAG enzymes (heparinase I, II, III, etc) was fractionated with SAX high performance liquid chromatography, affording oligosaccharides that were sufficiently pure for structural characterization by LC-MS.

Body weight change. There were no significantly differences in total mean body weight between control and treatment groups at the beginning of treatment (Fig. 2A): DB-Hetero, $28.8 \pm 0.5 \mathrm{~g}$; DB-Homo, $45.4 \pm 0.6 \mathrm{~g}$; HEG5, $48.3 \pm 0.8 \mathrm{~g} ; \mathrm{CaG} 5,47.7 \pm 1.1 \mathrm{~g}$; IQG5, $46.6 \pm 1.3 \mathrm{~g}$; and Metformin 10, $50.0 \pm 0.9 \mathrm{~g}$. However, body weights of mice at the end of 4-week treatment were lower than those of control mice in Db-Homo groups: DB-Hetero, $30.1 \pm$ $0.4 \mathrm{~g}$; DB-Homo, $48.1 \pm 1.6 \mathrm{~g}(100 \%)$; HEG5, $43.0 \pm 0.7 \mathrm{~g}$ (89.4\%, HeG5 vs. DB-Homo, $p<0.05)$; CaG5, $41.3 \pm 2.2 \mathrm{~g}$ $(86.0 \%$, CaG5 vs. DB-Homo, $p<0.05)$; IQG5, $42.3 \pm$ $2.4 \mathrm{~g}, 87.3 \%$ ); and Metformin 10, $50.0 \pm 0.8$.

Effect of CaG5 on blood glucose level. First, we examined blood glucose levels after a single administration of $\mathrm{CaG}$ in $\mathrm{db} / \mathrm{db}$ mice and observed a reduction in blood glucose levels as shown previously (11). Glucose levels of homozygous $\mathrm{db}$ mice were increased with aging, from $316 \mathrm{mg} / \mathrm{dL}$ at age of 12 -week to $519 \mathrm{mg} / \mathrm{dL}$ at age of 17-week. Mean glucose levels in treatment groups were as follows: DB-Hetero (normal), $168.85 \pm 5.66 \mathrm{mg} / \mathrm{dL}$; DBhomo, $508.9 \pm 14.5 \mathrm{mg} / \mathrm{dL}$; HEG5, $486.7 \pm 83.5 \mathrm{mg} / \mathrm{dL}$; CaG5, $389.4 \mathrm{mg} / \mathrm{dL}$; IQG5, $414.6 \pm 137.1 \mathrm{mg} / \mathrm{dL}$; and Metformin $10,455.6 \pm 56.7 \mathrm{mg} / \mathrm{dL}$ (Fig. 2B). Although metformin did not present better efficacy in lowering blood glucose level than other GAGs because metformin was used at a low dose, blood glucose levels in GaG5 treated groups were significantly lower than those in the control group. 
(A)
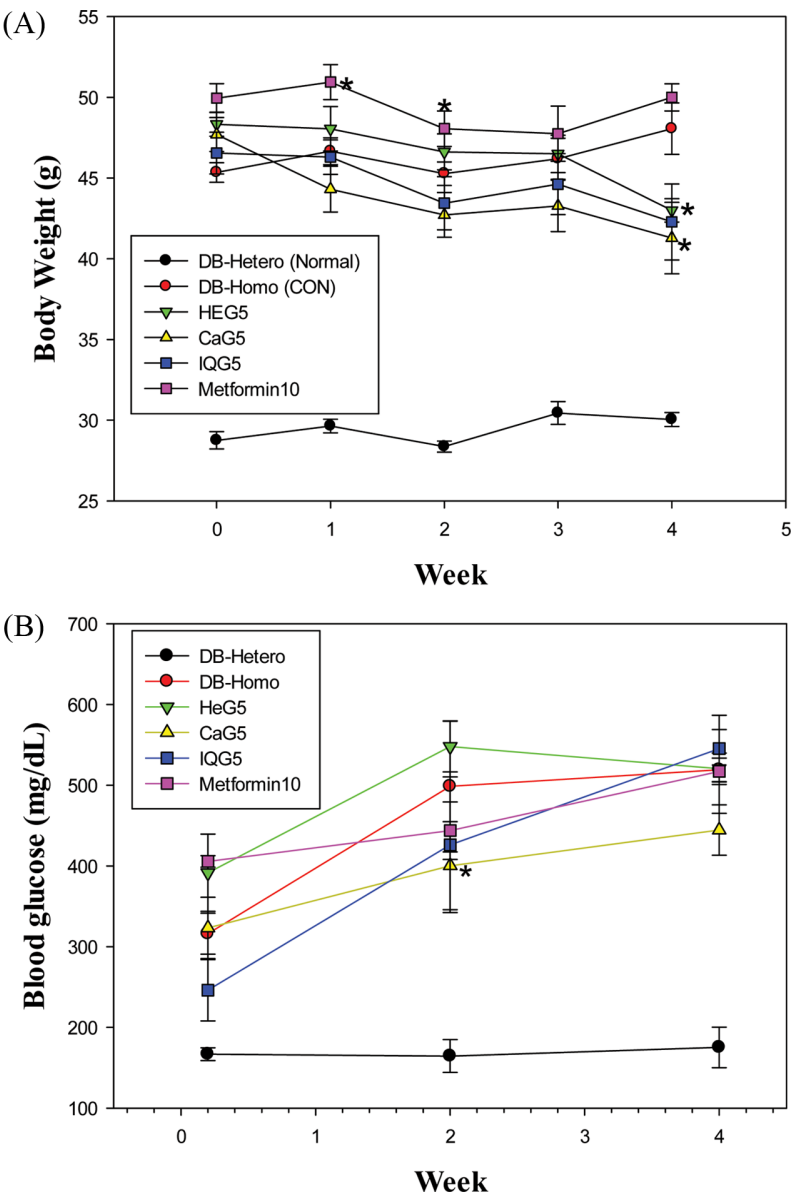

Fig. 2. Body weight and blood glucose level of $\mathrm{db}$ mice treated with dung beetle glycosaminoglycan for a one month. [sample group vs. CON (DB-Homo), ${ }^{*} p<0.05$ ].

Abdominal fat weight and adipocyte density. Abdominal fat weight $(\mathrm{g})$ of each treated GAG group was significantly differences from DB-Hetero (normal $\mathrm{db}$ mice) group but was no significantly difference from DB-Homo group: DB-Hetero, $0.55 \pm 0.26$; DB-Homo, $3.34 \pm 0.50$; HEG5, $3.35 \pm 0.22$; CaG5, $2.99 \pm 0.55$; IQG5, $2.80 \pm 1.39$; Metformin 10, $3.95 \pm 0.53$.

Adipocyte density tissues from treated $\mathrm{db}$ mice were significantly reduced by DB-Homo, $38 \pm 1.40(100 \%)$; HEG5, $22 \pm 0.92$ (57.9\%); CaG5, $19 \pm 2.22$ (50.0\%, CaG5 vs. DB-Homo, $p<0.05)$; IQG5, $21 \pm 0.92$ (55.3\%, IQG5 vs. DB-Homo, $p<0.05)$ and Metformin 10, $23 \pm 0.35$ (60.5\%) (Fig. 3).

Sero-biochemical finding of $\mathbf{d b}$ mice after treatment with insect GAG. Sera parameters from the CaG5- and IQG5-treated groups (Table 2) were also significantly lower than those in the control group at one month after treatment. Serum albumin levels $(\mathrm{g} / \mathrm{dL})$ in GAG treated groups were significantly lower than those in the control: DB-

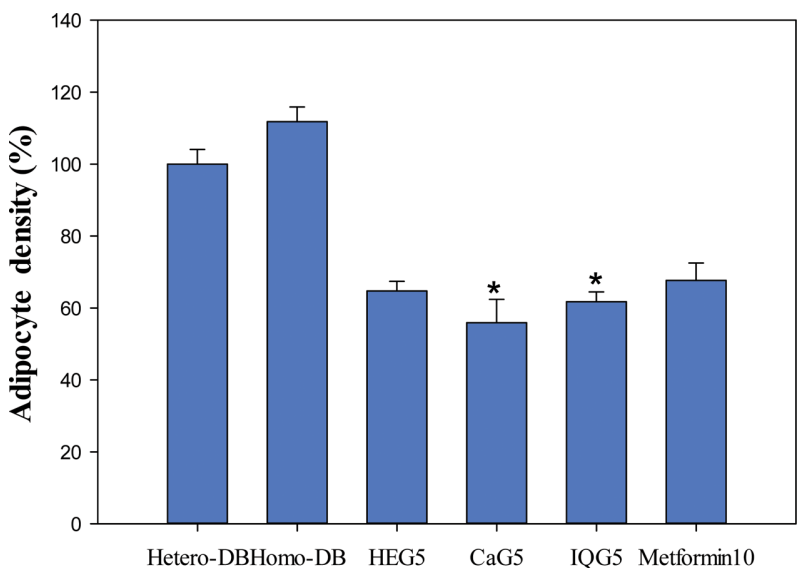

Fig. 3. Adipose tissue ratio (\%) of $\mathrm{db}$ mice treated with $C$. molossus glycosaminoglycan. The adipocyte cell density was counted from $\mathrm{db}$ mouse liver tissue toluidine blue $\mathrm{O}$ stained depots $\left({ }^{*} p<0.05\right)$.

Homo (CON), $3.8 \pm 0.3$; GaG5, $3.23 \pm 0.15$ (CaG5 vs. $\mathrm{CON}, p<0.05$ ); IQG5, $2.83 \pm 0.17$ (IQG5 vs. CON, $p<$ $0.01)$. Free fatty acid levels in IQG-treatment $\mathrm{db}$ mice $(\mu \mathrm{Eq} / \mathrm{L})$ were also significantly lower than those in the control: CON, $1310.3 \pm 125.6$; IQG5, $765.8 \pm 121.4$ (IQG5 vs. CON, $p<0.001$ ). Creatinine phosphokinase levels (U/ L) were also decreased: DB-Hetero, $314.75 \pm 51.3$; DBHomo, 603.3 \pm 294.8; HEG5, $217 \pm 8.4 ;$ CaG5, $251.7 \pm$ 49.9; IQG5, 288.75 \pm 163.5; and Metformin 10, $224 \pm$ 20.52. Alkaline phosphatase (ALP) levels (U/L) in IQG5and $\mathrm{CaG} 5$-treated groups were also significantly lower than those in the control groups: CON, 109.33 \pm 12.34 ; $\mathrm{CaG} 5,73.3 \pm 7.0$ (CaG5 vs. CON, $p<0.05$ ); IQG5, $70.0 \pm$ 12.6 (IQG5 vs. CON, $p<0.001$ ). Mean total cholesterol levels $(\mathrm{mg} / \mathrm{dL})$ in $\mathrm{HeG}$ - or IQG-treated $\mathrm{db}$ mice were also significantly lower than those in the control group: $\mathrm{CON}, 222.7 \pm 13.2$; HeG5, $170 \pm 14.1$ (HeG5 vs. CON, $p<0.05$ ); IQG5, $171 \pm 18.7$ (IQG5 vs. CON, $p<0.05$ ) (Table 2, Fig. 4). These serological results showed that these GAGs could play a role in the cure against increased blood glucose, hyperglycemia, and complicated diseases.

Decrease of oxidative damage. Protein oxidative cellular stress was evaluated by measuring carbonyl content in blood neutrophil. Protein carbonyl concentrations in blood were decreased after treatment with insect glycosaminoglycans. Decreased ratios were $58.51 \%, 52.36 \%$, $55.80 \%$ and $50 \%$ for HeG5 (HeG5 vs. CON, $p<0.05$ ), CaG5 (CaG5 vs. CON, $p<0.05$ ), IQG5 (IQG5 vs. CON, $p<0.05$ ), and Metformin10 (Metformin10 vs. CON, $p<$ $0.05)$ groups, respectively. However, there were no statistical differences in hepatocyte carbonyl contents between control and treatment groups of db mice (Table 3, Fig. 5). Therefore, protein oxidative damages could be reduced by 
Table 2. Serological findings of db mice treated intraperitoneally with Heuchys, C. molossus or queen of B. ignitus, glycosaminoglycan over an one month

\begin{tabular}{|c|c|c|c|c|c|c|c|c|}
\hline Function & Parameter & Unit & DB-Hetero & $\begin{array}{c}\text { DB-Homo } \\
(\mathrm{CON})\end{array}$ & HeG5 & CaG5 & IQG5 & Metformin 10 \\
\hline Tonic & Albumin & $\mathrm{g} / \mathrm{dL}$ & $2.88 \pm 0.05$ & $3.8 \pm 0.3$ & $3.8 \pm 0$ & $3.23 \pm 0.15^{*}$ & $2.83 \pm 0.17^{* *}$ & $3.73 \pm 0.15$ \\
\hline \multirow[t]{2}{*}{ Fatty liver } & Free fatty acid & $\mu \mathrm{Eq} / \mathrm{L}$ & $712.75 \pm 53.34$ & $1310.3 \pm 125.6$ & $1749.5 \pm 61.5$ & $1093.7 \pm 164.4$ & $765.8 \pm 121.4^{* *}$ & $1016 \pm 30.51$ \\
\hline & ALP & $\mathrm{U} / \mathrm{L}$ & $60 \pm 16.73$ & $109.33 \pm 12.34$ & $114 \pm 17.0$ & $73.3 \pm 7.0^{*}$ & $70 \pm 12.6^{* *}$ & $127 \pm 13.45$ \\
\hline \multirow[t]{2}{*}{ Hepatitis } & AST (SGOT) & $\mathrm{U} / \mathrm{L}$ & $92 \pm 16.47$ & $110.5 \pm 14.85$ & $123 \pm 50.9$ & $109.3 \pm 2.5$ & $129.5 \pm 65.6$ & $120 \pm 20.07$ \\
\hline & ALT (SGPT) & $\mathrm{U} / \mathrm{L}$ & $39.75 \pm 3.4$ & $77 \pm 11.31$ & $74.5 \pm 17.7$ & $68.7 \pm 6.4$ & $92.5 \pm 66.7$ & $91.33 \pm 20.98$ \\
\hline Heart function & CK (SE) & $\mathrm{U} / \mathrm{L}$ & $314.75 \pm 51.3$ & $603.3 \pm 294.8$ & $217 \pm 8.4$ & $251.7 \pm 49.9$ & $288.75 \pm 163.5$ & $224 \pm 20.52$ \\
\hline Diabetes & Glucose (S) & $\mathrm{mg} / \mathrm{dL}$ & $195 \pm 24.45^{* *}$ & $660.3 \pm 78.8$ & $732 \pm 25.5$ & $543 \pm 139.4$ & $663.3 \pm 73.0$ & $750 \pm 0$ \\
\hline \multirow{4}{*}{ Lipidemia } & Cholesterol, total & $\mathrm{mg} / \mathrm{dL}$ & $130.25 \pm 7.85$ & $222.7 \pm 13.2$ & $170 \pm 14.1^{*}$ & $228.7 \pm 48.9$ & $171 \pm 18.7^{*}$ & $201 \pm 9.85$ \\
\hline & Triglyceride & $\mathrm{mg} / \mathrm{dL}$ & $126.5 \pm 12.12$ & $253.5 \pm 43.4$ & $274 \pm 8.49$ & $229 \pm 28.8$ & $240.3 \pm 22.8$ & $205 \pm 15.72$ \\
\hline & LDL cholesterol & $\mathrm{mg} / \mathrm{dL}$ & $25 \pm 2.83$ & $51.33 \pm 3.06$ & $11 \pm 0$ & $55.7 \pm 22.3$ & $35.8 \pm 11.6$ & $34.33 \pm 3.06^{*}$ \\
\hline & HDL cholesterol & $\mathrm{mg} / \mathrm{dL}$ & $90 \pm 10.55$ & $120 \pm 0$ & $120 \pm 0$ & $120 \pm 0$ & $108 \pm 8.9$ & $120 \pm 0$ \\
\hline \multirow{3}{*}{ Nepritis } & Creatinine & $\mathrm{mg} / \mathrm{dL}$ & $0.2 \pm 0.003$ & $0.32 \pm 0.03$ & $0.34 \pm 0.01$ & $0.29 \pm 0.06$ & $0.28 \pm 0.03$ & $0.36 \pm 0.02$ \\
\hline & BUN & $\mathrm{mg} / \mathrm{dL}$ & $23.63 \pm 0.74$ & $23.1 \pm 4.01$ & $24.2 \pm 2.4$ & $24.2 \pm 2.6$ & $19.2 \pm 3.7$ & $22.3 \pm 3.12$ \\
\hline & $\mathrm{Na}$ (Sodium) & $\mathrm{mmol} / \mathrm{L}$ & $148 \pm 2.16$ & $147 \pm 1.73$ & $153.5 \pm 6.4$ & $150.7 \pm 4.7$ & $148 \pm 3.5$ & $151.33 \pm 2.52$ \\
\hline \multirow[t]{2}{*}{ Hypertension } & Calcium & $\mathrm{mg} / \mathrm{dL}$ & $11.8 \pm 0.37^{* *}$ & $13.83 \pm 0.23$ & $13.8 \pm 0.28$ & $14.5 \pm 0.7$ & $14.05 \pm 0.7$ & $14.2 \pm 0.56$ \\
\hline & $\mathrm{Cl}$ (Chloride) & $\mathrm{mmol} / \mathrm{L}$ & $103 \pm 3.46^{*}$ & $94.33 \pm 2.89$ & $99.0 \pm 5.66$ & $99.0 \pm 6.9$ & $96.3 \pm 3.9$ & $102.67 \pm 2.08^{*}$ \\
\hline Edema & Protein, total (S) & $\mathrm{mmol} / \mathrm{L}$ & $5.68 \pm 0.19^{* *}$ & $7.87 \pm 0.31$ & $7.7 \pm 0.14$ & $7.53 \pm 0.67$ & $7.05 \pm 0.56$ & $7.57 \pm 0.21$ \\
\hline Rheumatis & CRP (HS) & $\mathrm{mg} / \mathrm{L}$ & $0.15 \pm 0.06$ & $0.3 \pm 0.1$ & $0.85 \pm 0.21$ & $0.37 \pm 0.12$ & $0.65 \pm 0.25$ & $0.67 \pm 0.06^{*}$ \\
\hline
\end{tabular}

Each value represents mean \pm SD statistically significant from control $\left({ }^{*} p<0.05,{ }^{* *} p<0.01\right)$.

Table 3. Antioxidant enzyme activities of dung beetle glycosaminoglycan in hepatocyte of $\mathrm{db}$ (+leptin) mice

\begin{tabular}{|c|c|c|c|c|c|c|c|c|}
\hline \multicolumn{2}{|c|}{$\begin{array}{l}\text { Anti-Oxydative enzyme } \\
\text { And }\end{array}$} & Unit & DB-Hetero & DB-Homo & HEG5 & CaG5 & IQG5 & Metformin10 \\
\hline \multicolumn{2}{|l|}{ Catalase } & $\mathrm{mg}$ protein/min & $13.07 \pm 1.17$ & $14.19 \pm 1.92$ & $17.52 \pm 3.69$ & $20.35 \pm 2.58^{*}$ & $15.44 \pm 2.38$ & $17.93 \pm 3.6$ \\
\hline \multicolumn{2}{|c|}{ Glutathione peroxidase } & unit/mg protein & $8.79 \pm 1.1$ & $9.25 \pm 0.9$ & $9.7 \pm 1.7$ & $12.0 \pm 0.8$ & $11.6 \pm 1.6$ & $11.34 \pm 1.0$ \\
\hline \multicolumn{2}{|c|}{ Glutathione-s-transeferase } & $\mathrm{nmol} / \mathrm{min} / \mathrm{ml}$ & $3.13 \pm 0.24$ & $3.51 \pm 0.29$ & $3.69 \pm 0.28$ & $3.93 \pm 0.09$ & $3.09 \pm 0.41$ & $3.37 \pm 0.28$ \\
\hline \multicolumn{2}{|c|}{ Superoxide dismutase } & $\mathrm{nmol} / \mathrm{min} / \mathrm{ml}$ & $254.58 \pm 38.57$ & $267.57 \pm 11.49$ & $299.87 \pm 16.44$ & $336.11 \pm 16.37^{*}$ & $320.28 \pm 37.38$ & $289.01 \pm 45.47$ \\
\hline \multirow{2}{*}{ Carbonyl content } & Hepatocyte & $\mathrm{nmol} / \mathrm{mg}$ protein & $8.7 \pm 2.0$ & $9.92 \pm 1.64$ & $8.29 \pm 2.21$ & $8.57 \pm 2.06$ & $8.93 \pm 2.25$ & $9.39 \pm 1.83$ \\
\hline & Blood & $\mathrm{nmol} / \mathrm{mg}$ protein & $5.07 \pm 0.73$ & $5.52 \pm 0.59$ & $3.23 \pm 0.42^{*}$ & $2.89 \pm 0.3^{*}$ & $3.08 \pm 0.29^{*}$ & $2.76 \pm 0.38^{*}$ \\
\hline
\end{tabular}

Each value represents mean \pm SE statistically significant from control ( $p<0.05)$. 

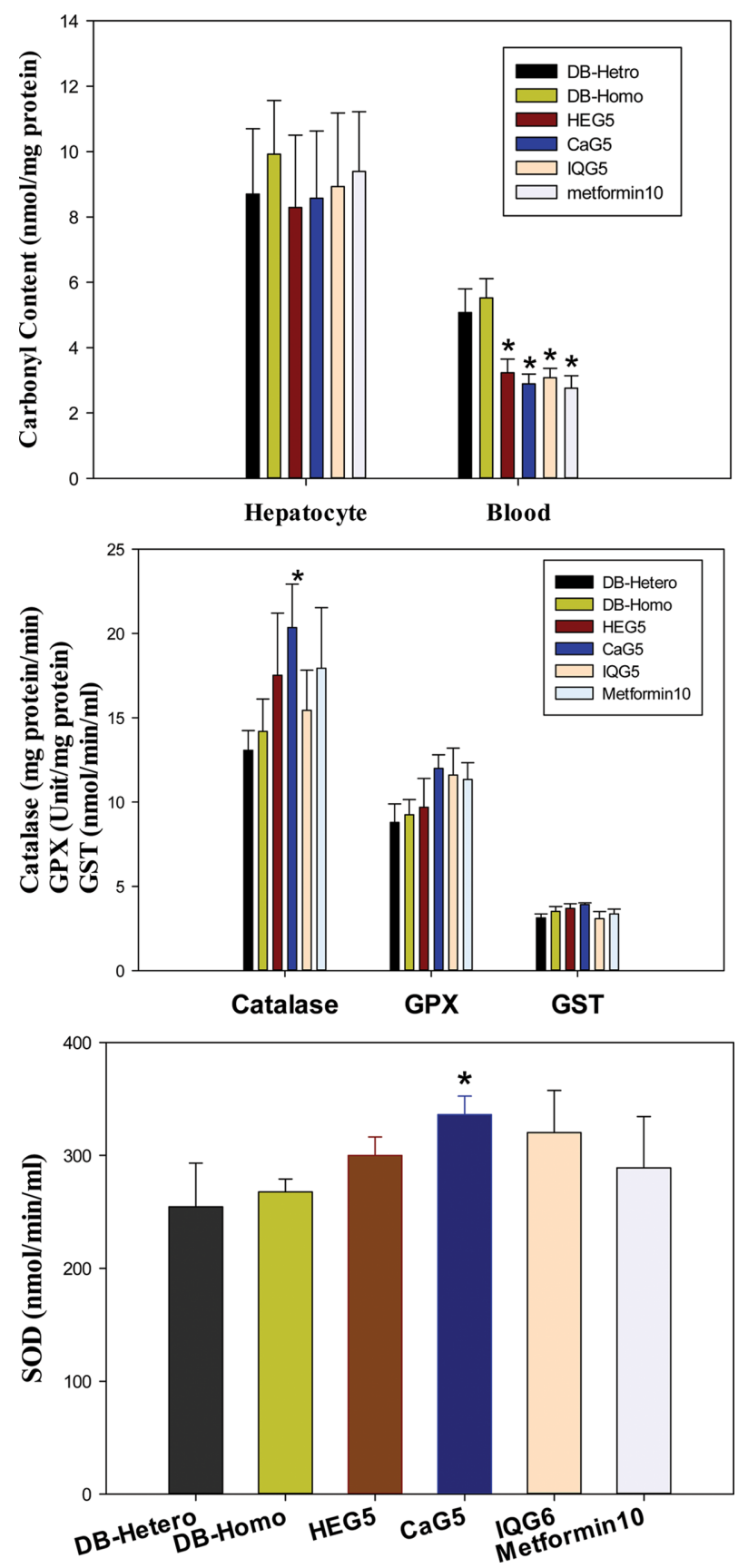

Fig. 4. Anti-oxidative effect of dung beetle glycosaminoglycan on proteins carbonyl, catalase, Glutathione peroxidase (GPX) or glutathione s-transferase (GTS) content, Super oxide dismutase (SOD) $\left({ }^{*} p<0.05\right)$.

theses GAGs.

Oxidative enzyme (catalase, GPx, GST, SOD) quantitation. Oxidative enzyme is a free radical scavenger enzyme. Level of enzymes such as catalase, GPx, GST, and SOD enzymes were increased by GAG at one month after treatment.

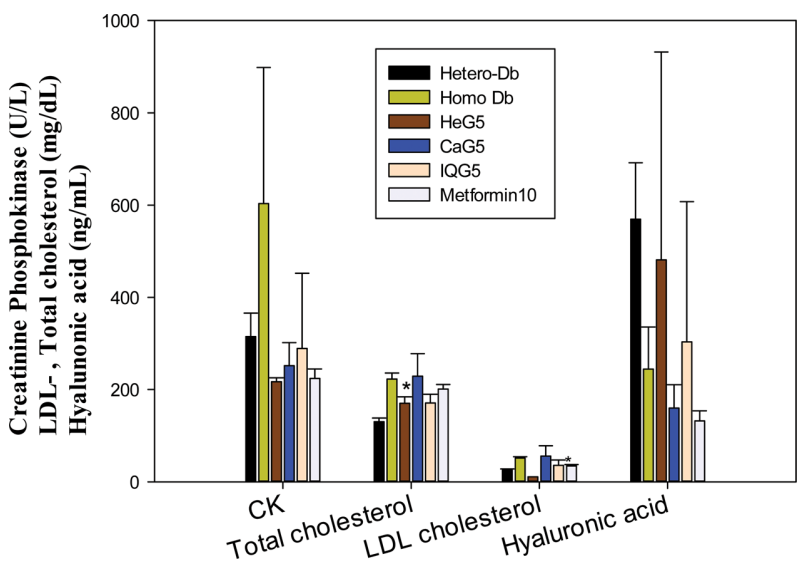

Fig. 5. Sero-biochemical detection of creatinine phosphokinase, LDL-/total cholesterol, hyaluronic acid in CaG-treated db mice $\left({ }^{*} p<0.05\right)$.

Catalase activites (mg protein/min) in db mice hepatocytes after one month of GAG treatment were as follows: $\mathrm{db}$ mice $(\mathrm{CON}), 14.19 \pm 1.92 ; \mathrm{HeG} 5,17.52 \pm 3.69$ (HeG5/ CON: 123\%); CaG5, $20.35 \pm 2.58$ (143\%, CaG5 vs. CON, $p<0.05)$; IQG5, $15.44 \pm 2.38$; and Metformin 10, $17.93 \pm$ 3.6 (Met/CON: 126\%). Catalase activities in all GAGtreated hepatocyte groups were increased compared to those in the control group. Glutathione peroxidase activities (Unit/mg protein) in all GAG treated groups were also increased: $\mathrm{db}$ mice $(\mathrm{CON}), 9.25 \pm 0.9$; HeG5, $9.7 \pm 1.7$; $\mathrm{CaG} 5,12.0 \pm 0.8$ (CaG5/CON: 129.7\%); IQG5, $11.6 \pm 1.6$ (IQG5/CON: 125.4\%); Metformin10, $11.34 \pm 1.0$ (Met/ CON: 122.6\%). Glutathione-s-transferase activities (nmol/ $\mathrm{min} / \mathrm{ml}$ ) were as follows: CON, $3.51 \pm 0.29$; HeG5, $3.69 \pm$ 0.28; CaG5, $3.93 \pm 0.09$ (CaG5/CON: 112.0\%); IQG5, $3.09 \pm 0.41$; and Metformin 10, $3.37 \pm 0.28$. Superoxide dismutase activities $(\mathrm{nmol} / \mathrm{min} / \mathrm{ml})$ were significantly increased in treatment groups: DB-Hetero (normal mice), $254.58 \pm 38.57$; db mice $(\mathrm{CON}), 267.57 \pm 11.49$; HeG5, $299.87 \pm 16.44$; CaG5, $336.11 \pm 16.37$ (125.6\%, CaG5 vs. CON, $p<0.05$ ); IQG5, 320.28 \pm 37.38 ; and Metformin10, $289.01 \pm 45.47$ (Table 3, Fig. 4).

Gene expression by quantitative real-time PCR analysis. Some genes were elucidated by real-time PCR. Data are presented as PCR cycle number ( $\mathrm{Ct}$ value) when concentration of PCR amplicon is equilibrated by sample amplicon. Median CT values of five samples (DB-Homo, HeG5, CaG5, IQG5, and Metformin10) are presented. Mean $\mathrm{Ct}$ value of treatment groups were as follows: heparanase: CON, 35.4; HeG5, 35.3; CaG5, 35.6: IQG5, 35.2; Metformin10, 35.4; Glutathione peroxidase 1 (Gpx1): CON, 26.9; HeG5, 27.0; CaG5, 26.8: IQG5, 26.8; Metformin 10, 26.8; glycogen synthase kinase 3 beta (GSK3b): CON, 26.3; HeG5, 26.5; CaG5, 26.4: IQG5, 26.2; Metformin10, 26.8. There were no significant differences in 
gene expression between treatment groups and the control group $(\mathrm{Ct}$ value $>2.0)$.

Gene expression profiling by DNA microarray. Microarray analysis using a Mouse $28 \mathrm{~K}$ cDNA clone array was performed in order to obtain gene-expression profiles for $\mathrm{HeG}, \mathrm{CaG}, \mathrm{IQG}$, and metformin-treated $\mathrm{db}$ mice livers. This might provide information for potential anti-diabetic markers (Table 4, 5). Compared to the control group, 49, 48, 279 and 225 genes were upregulated $(>2$ fold increase, Table 3) 83, 79, 679 and 110 genes were downregulated ( $>2$-fold decrease, Table 5) in $\mathrm{HeG}, \mathrm{CaG}$, IQG, and metformin-treated groups. Therefore, IQG-treatment showed the most effect on gene expression in the liver of $\mathrm{db}$ mice. An overview of these genes revealed 19 functional categories, including genes, 49 homeostatic process

Table 4. Upregulated genes differentially expressed in liver tissue of $\mathrm{db}$ mice treated with GAG over a 1-month period

\begin{tabular}{|c|c|c|c|c|c|c|}
\hline Index & Gene description & Genesymbol & HeG5 & CaG5 & IQG5 & Met10 \\
\hline 1 & Mitochondriallyen coded tRNAlysine & mt-Tk & 2.19 & 9.64 & 1.76 & 1.28 \\
\hline 2 & Cytochrome P450, family8, subfamilyb, polypeptide1 & Cyp8b1 & 3.35 & 8.34 & 1.25 & 1.48 \\
\hline 3 & 5 Nucleotidase, ecto & $\mathrm{Nt5e}$ & 2.01 & 6.34 & 1.21 & 1.61 \\
\hline 4 & Myo-inositol1-phosphatesynthaseA1 & Isyna1 & 2.23 & 6.28 & 1.43 & 1.61 \\
\hline 5 & CytochromeP450, family2, subfamilyb, polypeptide 10 & Cyp2b10 & 3.17 & 4.86 & 1.32 & 1.32 \\
\hline 6 & Immunoglobulin kappa variable 4-55 & Igkv4-55 & 3.23 & 4.77 & 1.03 & 1.79 \\
\hline 7 & Immunoglobulin kappa chainvariable 4-72 & Igkv4-72 & 2.20 & 4.50 & 1.23 & 1.08 \\
\hline 8 & Gprotein-coupled receptor, familyC, group5, memberA & Gprc5a & 2.20 & 4.50 & 1.12 & 1.36 \\
\hline 9 & Murinoglobulin, pseudogene1 & Mug-ps1 & 2.04 & 4.46 & 1.70 & 1.12 \\
\hline 10 & Immunoglobulin kappa chain complex & Igk & 2.10 & 4.44 & 1.16 & 1.64 \\
\hline 11 & PTC7 protein phosphatase homolog (S.cerevisiae) & Pptc7 & 2.12 & 4.18 & 1.35 & 1.71 \\
\hline 12 & Thioredoxinin teracting protein & Txnip & 3.03 & 3.97 & 1.00 & 1.46 \\
\hline 13 & CD59a antigen & $\mathrm{Cd} 59 \mathrm{a}$ & 2.12 & 3.90 & 1.87 & 1.80 \\
\hline 14 & Odorant binding protein $2 \mathrm{~A}$ & Obp2a & 2.01 & 3.80 & 1.15 & 1.91 \\
\hline 15 & CytochromeP450, family2, subfamilyc, polypeptide39 & Cyp2c39 & 2.57 & 3.75 & 1.07 & 1.67 \\
\hline 16 & Angiopoietin-like4 & Angptl4 & 2.05 & 3.75 & 1.07 & 1.35 \\
\hline 17 & CytochromeP450, family 39 , subfamilya, polypeptide 1 & Cyp39a1 & 2.00 & 3.74 & 1.09 & 1.55 \\
\hline 18 & MicroRNA5125 & Mir5125 & 2.06 & 3.71 & 1.12 & 1.14 \\
\hline 19 & Serine/arginine repetitive matrix 2 & Srrm2 & 2.38 & 3.62 & 1.05 & 1.12 \\
\hline 20 & StefinA2 like1 & Stfa211 & 2.03 & 3.62 & 1.46 & 1.32 \\
\hline 21 & $\begin{array}{l}\text { Immunoglobulin heavy joining2| immunoglobulin heavy } \\
\text { variable14-2 }\end{array}$ & Ighj2|Ighv14-2|Ighm|Ighj1 & 2.28 & 3.42 & 1.99 & 1.31 \\
\hline 22 & $\begin{array}{l}\text { Solute carrier family } 13 \text { (sodium-dependent citrate trans- } \\
\text { porter), member5 }\end{array}$ & Slc13a5 & 2.02 & 3.40 & 1.01 & 1.34 \\
\hline 23 & Vanin 1 & Vnn1 & 2.12 & 3.33 & 1.27 & 1.81 \\
\hline 24 & Chitinase3-like1 & Chi311 & 2.82 & 3.28 & 1.28 & 1.89 \\
\hline 25 & Amino carboxy muconatesemialdehyde decarboxylase & Acmsd & 2.43 & 3.23 & 1.09 & 1.84 \\
\hline 26 & Predictedgene 5068 & Gm5068 & 1.52 & 3.22 & 1.97 & 1.01 \\
\hline 27 & Retinol binding protein1, cellular & Rbp1 & 1.81 & 3.21 & 1.16 & 1.04 \\
\hline 28 & Ubiquitin specific peptidase 2 & Usp2 & 1.95 & 3.14 & 1.45 & 1.95 \\
\hline 29 & $\begin{array}{l}\text { Homocysteine-inducible, endoplasmicreticulumstress- } \\
\text { inducible, ubiquitin-likedomainmember1 }\end{array}$ & Herpud1 & 1.64 & 3.14 & 1.56 & 1.52 \\
\hline 30 & Predictedgene 15889 & Gm15889 & 1.33 & 3.14 & 1.48 & 1.33 \\
\hline 31 & Tumor necrosis factor receptor superfamily,member 23 & Tnfrsf23 & 1.34 & 3.13 & 1.42 & 1.04 \\
\hline 32 & RIKENcDNA1810008I18 gene & 1810008I18Rik & 1.77 & 3.06 & 1.29 & 1.31 \\
\hline 33 & $\begin{array}{l}\text { Immunoglobulin kappa chain complex| immunoglobu- } \\
\text { linkappavariable8-19| immunoglobulinkappajoining5 }\end{array}$ & Igk|Igkv8-19|Igkj5 & 1.99 & 3.05 & 1.72 & 1.62 \\
\hline 34 & Cytochrome P450, family51 & Cyp51 & 1.50 & 2.94 & 1.79 & 1.49 \\
\hline 35 & Secreted phosphoprotein 1 & Spp1 & 1.91 & 2.88 & 1.75 & 1.23 \\
\hline 36 & Phosphogluconated ehydrogenase & Pgd & 1.31 & 2.85 & 1.21 & 1.16 \\
\hline 37 & GlutathioneS-transferase, mu3 & Gstm3 & 1.40 & 2.84 & 1.54 & 1.42 \\
\hline 38 & Farnesyl diphosphate synthetase| predictedgene 3571 & Fdps $\mid \mathrm{Gm} 3571$ & 1.84 & 2.76 & 1.01 & 1.36 \\
\hline 39 & Carbonic anhydrase 3 & Car3 & 1.66 & 2.76 & 1.80 & 1.86 \\
\hline 40 & Olfactory receptor 205 & Olfr205 & 1.99 & 2.73 & 1.34 & 1.42 \\
\hline
\end{tabular}


Table 5. Downregulated genes differentially expressed in liver tissue of db mice treated with GAG over a 1-month period

\begin{tabular}{|c|c|c|c|c|c|c|}
\hline Index & Gene description & Genesymbol & HeG5 & CaG5 & IQG5 & Met10 \\
\hline 1 & S100 calcium binding proteinA8 (calgranulinA) & S100a8 & -5.17 & -4.86 & -2.33 & -2.99 \\
\hline 2 & $\begin{array}{l}\text { Immunoglobulin kappachaincomplex | immunoglobu- } \\
\text { linkappavariable6-23 }\end{array}$ & Igk|Igkv6-23|Igk-V28|Igkc & -6.61 & -4.50 & 1.02 & -2.30 \\
\hline 3 & $\begin{array}{l}\text { Interferon-inducibleGTPase1-like|cDNAsequence- } \\
\text { BC023105 }\end{array}$ & LOC630751|BC023105 & -3.68 & -4.50 & -6.16 & -3.24 \\
\hline 4 & Fatty acid synthase & Fasn & -2.82 & -4.46 & -1.35 & -1.06 \\
\hline 5 & $\begin{array}{l}\text { Immunoglobulinheavyconstantmulimmunoglobulinheavy- } \\
\text { chain (J558family)| immunoglobulinheavyconstantgam- } \\
\text { ma1 (G1mmarker) }\end{array}$ & Ighm|Igh-VJ558|Ighg1 & -5.44 & -4.18 & -1.88 & -4.86 \\
\hline 6 & CyclinD1 & Ccnd1 & -3.27 & -3.80 & -1.87 & -6.24 \\
\hline 7 & Neutrophilic granule protein & Ngp & -3.77 & -3.75 & -3.46 & -3.10 \\
\hline 8 & $\begin{array}{l}\text { Immunoglobulin heavychain (X24family)| immunoglobu- } \\
\text { lin heavychain (J558family) }\end{array}$ & $\begin{array}{l}\text { Igh-VX24|Igh- } \\
\text { VJ558|Igha|Ighm|Ighg| } \\
\text { Ighg3|Ighj4|Ighv14-2 }\end{array}$ & -4.52 & -3.74 & -1.07 & -2.50 \\
\hline 9 & S100 calcium binding proteinA9 (calgranulinB) & S100a9 & -4.24 & -3.71 & -4.22 & -3.09 \\
\hline 10 & Lymphocyte antigen 6 complex, locusD & Ly6d & -1.51 & -3.62 & -2.25 & -2.37 \\
\hline 11 & Tubulin, beta2A classIIA & Tubb2a & -1.94 & -3.56 & -1.95 & -1.28 \\
\hline 12 & 3-Hydroxy-3-methylglutaryl-CoenzymeA synthase1 & Hmges1 & -1.31 & -3.42 & -2.02 & -1.10 \\
\hline 13 & Lactotransferrin & Ltf & -3.18 & -3.33 & -2.70 & -2.94 \\
\hline 14 & RIKENcDNA9030619P08gene & 9030619P08Rik & -2.41 & -3.28 & -3.34 & -1.86 \\
\hline 15 & InterferoninducibleGTPase1 | cDNAsequenceBC023105 & Iigp1|BC023105 & -2.77 & -3.23 & -3.63 & -2.43 \\
\hline 16 & Lymphocyte antigen 6complex, locusC2 & Ly6c2 & -2.63 & -3.22 & -2.41 & -2.08 \\
\hline 17 & Murinoglobulin2 & Mug2 & -4.48 & -3.21 & -15.04 & -1.00 \\
\hline 18 & Squalene epoxidase & Sqle & -1.62 & -3.14 & -1.32 & -1.62 \\
\hline 19 & $\begin{array}{l}\text { Immunoglobulin kappachaincomplex | V(kappa)gene- } \\
\text { product|immunoglobulinkappachainvariable28 (V28) } \mid \\
\text { immunoglobulinkappajoining1 }\end{array}$ & $\begin{array}{l}\text { Igk|LOC672450|Igk- } \\
\text { V28|Igkj1 }\end{array}$ & -3.22 & -3.14 & -3.47 & -2.20 \\
\hline 20 & Monooxygenase, DBH-like1 & Moxd1 & -2.94 & -3.14 & -1.91 & -2.44 \\
\hline 21 & Glycoprotein 49A & Gp49a & -3.06 & -3.06 & -2.73 & -2.07 \\
\hline 22 & Farnesyl diphosphate synthetase | predictedgene 3571 & Fdps $\mid \mathrm{Gm} 3571$ & -1.84 & -3.05 & -1.01 & -1.36 \\
\hline 23 & $\begin{array}{l}\text { S100 calciumbinding proteinA11 (calgizzarin) } \mid \text { predict- } \\
\text { edgene } 12854 \mid \text { predictedgene } 5068\end{array}$ & $\begin{array}{l}\mathrm{S} 100 \mathrm{a} 11|\mathrm{Gm} 12854| \mathrm{Gm} 50 \\
\quad 68\end{array}$ & -1.69 & -2.85 & -2.16 & -1.33 \\
\hline 24 & Heatshockprotein 8 & Hspa8 & -2.42 & -2.84 & -1.95 & -2.15 \\
\hline 25 & $\begin{array}{l}\text { Immunoglobulin heavychain (gammapolypeptide) } \\
\text { immunoglobulin heavyconstantmu|immunoglobulin- } \\
\text { heavyconstantgamma2B }\end{array}$ & Ighg|Ighm|Ighg2b & -2.73 & -2.73 & -1.26 & -1.75 \\
\hline 26 & SerumamyloidP-component & Apcs & -3.06 & -2.67 & -4.56 & -2.12 \\
\hline 27 & ATPcitratelyase & Acly & -1.86 & -2.64 & -1.20 & -1.03 \\
\hline 28 & $\begin{array}{l}\text { U1b2 small nuclear RNA| U1b6 small nuclear RNA } \\
\text { |U1b1smallnuclearRNA }\end{array}$ & Rnu1b2|Rnu1b6|Rnu1b1 & -2.95 & -2.61 & -3.28 & -2.55 \\
\hline 29 & CytochromeP450, family51 & Cyp51 & -1.50 & -2.60 & -1.79 & -1.49 \\
\hline 30 & Small nucleolar RNA, H/ACA box62 & Snora62 & -2.17 & -2.58 & -2.67 & -3.66 \\
\hline 31 & Interleukin1 beta & Illb & -2.34 & -2.53 & -1.89 & -1.51 \\
\hline 32 & Immunoglobulin kappa chain complex & Igk & -2.15 & -2.51 & -1.41 & -1.93 \\
\hline 33 & Immunoglobulin heavy chain (J558family) & Igh-VJ558 & -2.74 & -2.50 & -1.57 & -2.28 \\
\hline 34 & $\begin{array}{l}\text { Leukocyte immunoglobulin-like receptor, subfamilyB, } \\
\text { member } 4\end{array}$ & Lilrb4 & -2.46 & -2.49 & -4.86 & -1.44 \\
\hline 35 & Olfactoryreceptor 205 & Olfr205 & -1.98 & -2.47 & -1.34 & -1.42 \\
\hline 36 & $\begin{array}{l}\text { Oredictedgene10106| predictedgene10717| predicted- } \\
\text { gene10721|predictedgene10716 }\end{array}$ & $\begin{array}{l}\mathrm{Gm} 10106|\mathrm{Gm} 10717| \mathrm{Gm} 1 \\
0721 \mid \mathrm{Gm} 10716\end{array}$ & -1.89 & -2.44 & -11.26 & -3.45 \\
\hline 37 & Predictedgene 15998 & Gm15998 & -2.00 & -2.41 & -2.45 & -1.24 \\
\hline 38 & Elastase, neutrophil expressed & Elane & -1.93 & -2.39 & -1.04 & -1.76 \\
\hline 39 & Resistinlike gamma & Retnlg & -2.37 & -2.37 & -1.36 & -2.37 \\
\hline 40 & $\begin{array}{l}\text { Serine (orcysteine) peptidase inhibitor, cladeA (alpha- } \\
\text { lantiproteinase, antitrypsin), member7 }\end{array}$ & Serpina7 & -1.91 & -2.33 & -3.55 & -1.71 \\
\hline
\end{tabular}


related genes that showed more changed in expression. Furthermore IQG- and metformin-treated group genes showed more changes in expression, especially in case of IQG-treated group. A total of 71 genes related to lipid metabolism were changed in expression in IQG-, and metformin- treated groups, especially in IQG-treated group. Only three genes showed changes in expression compared to control group. They were associated with cell growth (Table 4, 5).

Compared to the control group, mitochondriallyen coded tRNA lysine (mt-TK) gene, encoding a mitochondrial thymidine kinase, was increased about 10-fold in CaG5treated group, 1.8-fold in the IQ5 group, and 2.2-fold in the HeG5 group. In liver tissues of CaG5-treated mice, cytochrome P450, family 8, subfamily b, polypeptide1 (Cyp8b1) was upregulated about 8.3-fold compared to that in control group. $\mathrm{CaG} 5$ treated mice group, compared to the control, 48 genes were up-regulated, including 5 ' nucleotidase ecto, myo-inositol1-phosphatate synthase A1, and cytochrome p450, family2, subfamily b, polypeptide 10 (Table 4), While, 79 genes were down-regulated, including S100 calcium binding protein A8 (calgranulin A), immunoglobulin kappa chain complex (Igk, IGkv6-23), interferon-inducible GTPase1-like, fatty acid synthase, immunoglobulin heavy constant mu, and cyclin D1 (Table 5). These data indicate that mitochondrial thymidine kinase and cytochrome p450 family $8 / 2$ as upregulated genes and calgranulin $\mathrm{A}$ and immunoglobulin kappa chain complex as downregulated genes might be markers of potential therapeutics that work as anti-diabetic agents.

\section{DISCUSSION}

Diabetes is a chronic disease that cannot be easily cured by therapeutic agents. Glycosaminoglycan could play a role in the cure against increased blood glucose, hyperglycemia and complicated diseases. Glomerular basement membrane is mainly consisted of type 4 collagen, laminin and heparan sulfate proteoglycan. Heparanase plays a role in beta-cell failure, in addition to its ability to increase glomerular basement membrane permeability due to loss of negatively charged heparin sulfate, leading to urinary protein excretion $(11,12)$. Results of the present study revealed that, after, treatment with each glycosaminoglycan, sera total protein levels were decreased (HEG5, 97.8\%; CaG5, 95.7\%; IQG5, 89.6\% and Metformin10, 96.1\%) compared to those in DB-Homo group. Furthermore, levels of total cholesterol, LDL cholesterol, and alkaline phosphatase were also decreased by these GAGs, demonstrating their anti-lipedema effects. It has been reported that only high-dose $(400 \mathrm{mg} / \mathrm{kg})$ metformin can significantly decrease blood glucose levels compared to vehicle alone. In contrast, little reduction, if any, was seen in mice treated with low-dose $(50 \mathrm{mg} / \mathrm{kg})$ of metformin (13). In the present study, db mice (12 16 weeks age) showed such a very high glucose state in severe diabetes that metformin did not recover blood glucose to normal level. Accordingly, the initial treatment dose at $10 \mathrm{mg} / \mathrm{kg}$ in $\mathrm{db}$ mice, equivalent of $600 \mathrm{mg} / 60 \mathrm{~kg}$ (commercially sold Diabex ${ }^{\mathrm{TM}}$ at a dose of $500 \mathrm{mg} / \mathrm{kg} / \mathrm{day}$ or $1,000 \mathrm{mg} / \mathrm{kg} /$ day) (14) in men, might not be sufficient enough to lower the blood glucose level. Metformin is widely used as a hypoglycemic reagent for type 2 diabetes. Nowadays, statin-metformin (antilipidemic-antidiabetic) combined complex drug preparation is used more in diabetes complex diseases than metformin.

Levels of anti-oxidative enzymes and activities of catalase, glutathione peroxidase, and glutathione-s-transferase were increased by these GaGs. Therefore, cellular oxidative stress by free radical damage could be scavenged with the help of these antioxidant enzymes. These cellular oxidative damage repairs could contribute to diabetic disease control not only by repairing hepatocytes, but also by repairing other organ cells including pancreatic and kidney cells. Recently, antioxidant and antithrombotic treatment has become a trend therapy for diabetic kidney disease besides the use classic agents, such as aspirin and novel drugs such as sulodexide (a type of glycosaminoglycan) and Chinese medicine such as lumbrikinase that shows beneficial effects on diabetic patients (1). In our $\mathrm{db}$ mice experiment, CaG5 appeared to have anti-oxidant activity, increasing activity of catalase by $143 \%$, GPX by $129.7 \%$, GST by $112.0 \%$ and SOD by $125.6 \%$. As a cellular oxidative damage, protein oxidative damage was also reduced (HEG5, 58.5\%; CaG5, 52.4\%; IQG5, 55.8\% and Metformin $10,50.0 \%$ ) by these GaGs based on blood neutrophil carbonyl content.

The most upregulated gene found in this study was a mitochondriallyen coded tRNA lysine (mt-TK) gene, an electron transporter related gene. It encodes a mitochondrial thymidine kinase that plays a role in aminoglycosideinduced nonsyndromic disorder. It affects the translation of all mitochondrial DNA encoded proteins and impairs the assembly of the electron transport chain complexes, leading to decreased mitochondrial respiratory function (15). The 2nd most upregulated gene in this study was found to be cytochrome P450, family 8 , subfamily b, polypeptide 1, sterol 12 alpha-hydroxylase (cyp8b) is a key enzyme for regulating cholic acid/chendeoxycholic acid ratio in bile biosynthesis (16). It is related to antilipedema and lipid digestion. Whereas, loss of Cyp8b1 improves glucose homeostasis by increasing GLP-1and Cyp8b1 results in improved glucose tolerance, insulin sensitivity, and beta-cell function, mediated by absence of cholic acid in Cyp8b12/2 mice (17).

Overviewing of acquired microarray data of $\mathrm{db}$ mice after GAG treatment, upregulated genes such as mitochondrial thymidine kinase (mt-TK), cytochrome P450, family 8/2(Cyp8b1/2b10), and immunoglobulin kappa variable 4-55/ 
Role of Bumblebee queen/Dung beetle glycosaminoglycan

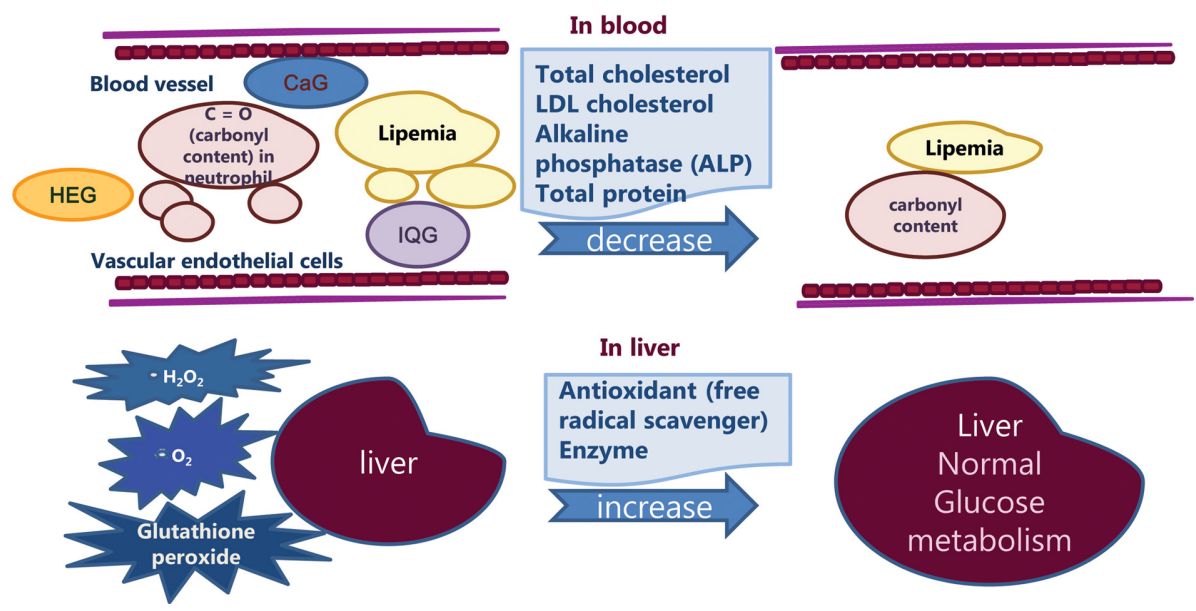

Fig. 6. Summary of GAG's mechanism of action in db mice.

72 (Igkv4-55/4-72) are related to decrease of cellular oxidative stress and increase of anti-oxidant enzyme capacity and quantity. In fact, a mitochondrial disease by a point mutation of mitochondrial DNA in mt-TK genes can be partially restored by coenzyme Q10. This indicates that glycosaminoglycan with antioxidant activities might be useful as therapeutic agents.

The most downregulated gene based on DNA microarray in this study was found to be $\mathrm{S} 100$ calcium binding protein A8 (S100A8, calgranulin A), an inflammatory molecules. A heterodimer of calprotectin with S100A9 has been reported (18). Decrease of neutrophil-derived S100 calcium - binding proteins A8/A9 could depress reticulated thrombocytosis and atherogenesis in diabetes suggesting suppress inflammatory molecule S100A9/A8 might have anti-diabetic effect (19). The 2nd most downregulated gene found in this study was immunoglobulin kappa chain complex (Igk, IGkv6-23), an immunoglobulin kappa variant 6-23 in house mouse (Mus musculus) (20).

In sera data of this study, creatinine kinase level as a cardiac inflammation marker was reduced by GAG treatment. GPRC5 is a potential tumor suppressor and oncogene with emerging roles in diseases (21). GPRC5 in this $\mathrm{db}$ mice study was upregulated with tumor suppression potential as a similar cure function. Cyclin D1 plays an important role in the regulation of G1 progression of somatic cell cycle by functioning as a regulatory submit of cdk4 and cdk6 (22). Increased expression of cyclinD (CcnD10) and Myc (MYC) genes are known to be involved in liver cancer. Results of this study showed their downregulation, indicating that these GAG could prevent liver cancer in $\mathrm{db}$ mice as indicated in a previous study (23).

These results from sero-biochemical, hepatocellular antioxidant assay, DNA gene expression profiling and $\mathrm{db}$ mice clinical data suggest $\mathrm{CaG}, \mathrm{IQG}$ and $\mathrm{HeG}$ could be used as natural anti-diabetic agents and functional food, like Sulodexide (24). Proposed mechanisms involved in the decrease of cellular oxidative stress in blood and liver tissues with increase of anti-oxidant enzyme in db mice after treatment with GAG are summarized in Fig. 6.

\section{ACKNOWLEDGMENTS}

The authors acknowledge National Academy of Agricultural Science for financial (RDA, PJ011853) and technical supports.

Received February 9, 2018; Revised March 9, 2018; Accepted March 14, 2018

\section{REFERENCES}

1. Yan, W., Zhou, B., Shen, Y. and Xu, G. (2015) Antioxidant and antithrombotic therapies for diabetic kidney disease. Iran. J. Kidney Dis., 9, 413-420.

2. Lepedda, A.J., Muro, P.D., Capobianco, G. and Formato, M. (2017) Significance of urinary glycosaminoglycans/proteoglycans in the evaluation of type 1 and type 2 diabetes complications. J. Diabetes Complicat., 31, 149-155.

3. Kubaski, F., Osago, H., Mason, R.W., Yamaguchi, S., Kobayashi, H., Tsuchiya, M., Orii, T. and Tomatsu, S. (2017) Glycosaminoglycans detection methods: application of mass spectrometry. Mol. Genet. Metab., 120, 67-77.

4. Li, R., Xing, J., Mu, X., Wang, H., Zhang, L., Zhao, Y. and Zhang, Y. (2015) Sulodexide therapy for the treatment of diabetic nephropathy, a meta-analysis and literature review. Drug Des. Devel. Ther., 9, 6275-6283.

5. Ahn, M.Y., Kim, B.J., Kim, H.J., Yoon, H.J., Jee, S.D., Hwang, J.S. and Park, K.K. (2017). Anti-obesity effect of Bombus ignitus queen glycosaminoglycans in rats on a highfat diet. Int. J. Mol. Sci., 18, E681. 
6. Ahn, M.Y., Kim, B.J., Kim, H.J., Hwang, J.S., Jung, Y.S. and Park, K.K. (2017) Anti-aging effect and gene expression profiling of dung beetle glycosaminoglycan in aged rats. Biomater. Res., 21, 5.

7. Xia, L., Bai, L., Yi, L., Liu, B., Chu, C., Liang, Z., Li, P., Jiang, Z. and Zhao, Z. (2007) Authentication of the 31 species of toxic and potent chinese materia medica (T/PCMM) by microscopic technique, part 1: three kinds of toxic and potent animal CMM. Microsc. Res. Tech., 70, 960-968.

8. Kim, Y.S., Jo, Y.Y., Chang, I.M., Toida, T., Park, Y. and Linhardt, R.J. (1996) A new glycosaminoglycan from the giant african snail Achatina fulica. J. Biol. Chem. 271, 1175011755.

9. Fratz, E.J., Hunter, G.A. and Ferreira, G.C. (2014) Expression of murine 5-aminolevulinate synthase variants causes protoporphyrin IX accumulation and light-induced mammalian cell death. PLoS ONE, 9, e93078.

10. Song, J., Liu, H., Ressom, H.W., Tiwari, S. and Ecelbarger, C.M. (2008) Chronic Rosigiltazone therapy normalizes expression of ACE1, SCD1 and other genes in the kidney of obese Zucker rats as determined by microarray by microarray analysis. Exp. Clin. Endocrinol. Diabetes, 116, 315-325.

11. Wang, F., Wan, A. and Rodrigues, B. (2013) The function of heparanase in diabetes and its complications. Can. J. Diabetes, 37, 332-338.

12. Ahn, M.Y., Hwang, J.S., Yoon, H.J. and Yun, E.Y. (2012) Anti-diabetic composition comprising glycosaminoglycans derived insect. Korean patient 10-120419.

13. Heishi, M., Ichihara, J., Teramoto, R., Itakura, Y., Hayashi, K., Ishikawa, H., Gomi, H., Sakai, J., Kanaoka, M., Taiji, M. and Kimura, T. (2006) Global gene expression analysis in liver of obese diabetic $\mathrm{db} / \mathrm{db}$ mice treated with metformin. Diabetologia, 49, 1647-1655.

14. Dou, J., Ma, J., Liu J., Wang, C., Johnsson, E., Yao, H., Zhao, J. and Pan, C. (2018) Efficacy and safety of saxagliptin in combination with metformin as initial therapy in Chinese patients with type 2 diabetes: results from the START study, a multicenter, randomized, double-blind, active-controlled, phase 3 trial. Diabetes Obes. Metab., 20, 590-598.

15. Mata, M.D.I., Garrido-Maraver, J., Cotán, D., Cordero, M.D., Oropesa-Ávila, M., Izquierdo, L.G., Miguel, M.D., Lorite, J.B., Infante, E.R., Ybot, P., Jackson, S. and SanchezAlcázar, J.A. (2012) Recovery of MERRF fibroblasts and cybrids pathophysiology by Coenzyme Q10. Neurotherapeutics, 9, 446-463.

16. Ishida, H., Yamashita, C., Kuruta, Y., Yoshida, Y. and Noshiro, M. (2000) Insulin is a dominant suppressor of sterol 12a-hydroxylase P450 (CYP8B) expression in rat liver possible role of insulin in Circadian rhythm of CYP8B. $J$. Biochem., 127, 57-64.

17. Kaur, A., Patankar, J.V., de Haan, W., Ruddle, P., Wijesekara, N., Groen, A.K., Verchere, C.B., Singaraja, R.R. and Hayden, M.R. (2015) Loss of cyp8b1 improves glucose homeostasis by increasing GLP-1. Diabetes, 64, 1168-1179.

18. Mortensen, O.H., Nielsen, A.R., Erikstrup, C., Plomgaard, P., Fischer, C.P., Krogh-Madsen, R., Lindegaard, B., Petersen, A.M., Taudorf, S. and Pedersen, B.K. (2009) Calprotectin - a novel marker of obesity. PLOS ONE, 4, e7419.

19. Kraakman, M.J., Lee, M.K.S., Al-Sharea, A., Dragoljevic, D., Barrett, T.J., Montenont, E., Basu, D., Heywood, S., Kammoun, H.L., Flynn, M., Whillas, A., Hanssen, N.M.J., Febbraio, M.A., Westein, E., Fisher, E.A., Chin-Dusting, J., Cooper, M.E., Berger, J.S., Goldberg, I.J., Nagareddy, P.R. and Murphy, A.J. (2017) Neutrophil-derived S100 calciumbinding proteins A8/A9 promote reticulated thrombocytosis and atherogenesis in diabetes. J. Clin. Invest., 127, 21332147.

20. Giudicelli, V., Chaume, D. and Lefranc, M. (2005) IMGT/ GENE-DB: a comprehensive database for human and mouse immunoglobulin and $\mathrm{T}$ cell receptor genes. Nucleic Acids Res., 33, D256-D261.

21. Zhou, H. and Rigoutsos, I. (2014) The emerging roles of GPRC5A in diseases. Oncoscience, 1, 765-776.

22. Tanaka, T., Kubota, M., Shinohara, K., Yasuda, K. and Kato, J. (2003) In vivo analysis of the cyclin D1 promotor during early embryogenesis in Xenopus. Cell Struct. Funct., 28, 165-177.

23. Chowdhury, K.H., Montgomery, M.K., Morris, M.J., Cognard, E., Shepherd, R.R. and Smith, G.C. (2015) Glucagon phosphorylate serine 552 of beta-catenin leading to increased expression of cyclinD1 and C-Myc in isolated rat liver. Arch. Physiol. Biochem., 121, 88-96.

24. Lauver, D.A. and Lucchesi, B.R. (2006) Sulodexide: a renewed interest in this glycosaminoglycan. Cardiovasc. Drug Rev., 24, 214-226. 